\title{
An analytical solution to slip buckling slope failure triggered by earthquake
}

\author{
Shengwen Qi ${ }^{\mathrm{a}, \mathrm{b}, *}$, Hengxing Lan ${ }^{\mathrm{a}, \mathrm{c}}$, Jinyu Dong ${ }^{\mathrm{d}}$ \\ ${ }^{a}$ Key Lab. of Shale Gas and Geoengineering, Institute of Geology and Geophysics, Chinese Academy of Sciences, Beijing, China \\ ${ }^{\mathrm{b}}$ Department of Civil \& Environmental Engineering, University of Alberta, Edmonton, Canada \\ c State Key Laboratory of Resources and Environmental Information System, Institute of Geographic Sciences and Natural Resources Research, Chinese Academy of Sciences, Beijing, China \\ d College of Resources and Environment, North China University of Water Conservancy and Hydroelectric Power, Zhengzhou, China
}

\section{A R T I C L E I N F O}

\section{Article history:}

Accepted 3 June 2014

Available online 19 June 2014

\section{Keywords:}

Analytical solution

Buckling failure

Tangjiashan coseismic landslide

Energy equilibrium theory

\begin{abstract}
A B S T R A C T
Slip buckling failure often occurs in slopes intersected by a set of discontinuities with approximately parallel to the surface. Post-earthquake investigations indicate that some slip buckling failures occurred during 2008 Wenchuan event. However, it is still difficult to evaluate the slip buckling failure triggered by earthquakes. In this paper, we give a thorough mechanical analysis to slip buckling slope, and present an analytical solution on slip buckling slope failure which fully considers both the effect of earthquake and pore water pressure based on energy equilibrium theory. Then we apply the methodology to Tangjiashan landslide. Comprehensive retrospective study indicates that Tangjiashan landslide is a typical buckling failure case triggered by Wenchuan earthquake. The application shows that the analytical solution can be used to evaluate the stability of the slope with potential buckling failure during earthquake.
\end{abstract}

(c) 2014 Elsevier B.V. All rights reserved.

\section{Introduction}

Slip buckling slope failure often occurs when the slope is intersected by a set of discontinuities approximately parallel to the surface forming a slabbing. The failure mechanism suggests that the slope dips more steeply than the angle of internal friction of slabs formed by discontinuities (Cavers, 1981). It often initiates as a translational sliding along a weak interlayer on the upper slope and then creates a bulge by buckling slabs near the toe of the slope. Buckling slope failure is often observed in a stratified sedimentary rock slope. It can also occur in a metamorphic rock slope, for example, in a slope dominated by phyllites where cleavage or schistosity is significant and regular (Froldi and Lunardi, 1995).

A number of studies have been conducted to understand the slip buckling slope failure mechanism. Cavers (1981) developed simple formulae for three possible cases of buckling: flexural buckling of plane slopes, three hinge-buckling of plane slopes and three-hinge buckling of curved slopes, and analyzed flexural buckling failures using the concept of Euler's formula. Sun (1988) treated the buckling of rock slabs as a beam stability problem using the elastic theory, and suggested an energy equilibrium principle for solving this problem. Pant and Adhikary (1999), and Adhikary et al. (2001) investigated the mechanism of flexural buckling failure of foliated rock slopes, using both explicit and implicit finite element numerical models in AFENA code (a

\footnotetext{
* Corresponding author at: Key Lab. of Shale Gas and Geoengineering, Institute of Geology and Geophysics, Chinese Academy of Sciences, Beijing, China.

E-mail address: qishengwen@mail.iggcas.ac.cn (S. Qi).
}

large deformation Cosserat continuum model). Qin et al. (2001) presented a catastrophe cusp model to study the failure mechanisms of the slip-buckling slope, and suggested the important role of the historical evolutionary process of slope on its failure. Recently, Pereira and Lana (2013) analyzed a buckling failure occurring in an open pit mine based on software Phase2. The effect of discontinuity strength such as stiffness and cohesion, and the in situ stress on the buckling failure was presented.

Post-earthquake investigations indicate that slip buckling slope failures often occur during earthquake. For example, slip buckling slope failure was observed in a huge landslide triggered by 2008 Wenchuan earthquake shown in Fig. 1 and the Chiu-fen-erh-shan landslide triggered by Chi-Chi earthquake (Wang et al., 2003). However, the effect of earthquake on such failure mode has not been well understood by previous researches i.e. Cavers (1981), Sun (1988), Pant and Adhikary (1999), and Adhikary et al. (2001). In this paper, an analytical solution on slip buckling slope failure is presented by considering the effect of earthquake as well as the pore water pressure. A typical case-Tangjiashan landslide triggered by Wenchuan Earthquake on May 12, 2008 is analyzed.

\section{Mechanical model and analytical solution to the slip-buckling slope failure}

Similar to Cavers (1981), Sun (1988) and Qin et al. (2001), the mechanical model of rock slope slab buckling is simplified as a beam stability problem in this paper, which is rational since both the length and the width of the rock slab are far larger than its thickness. The mechanical model is shown in Fig. 2, in which $l$ is the buckling segment 


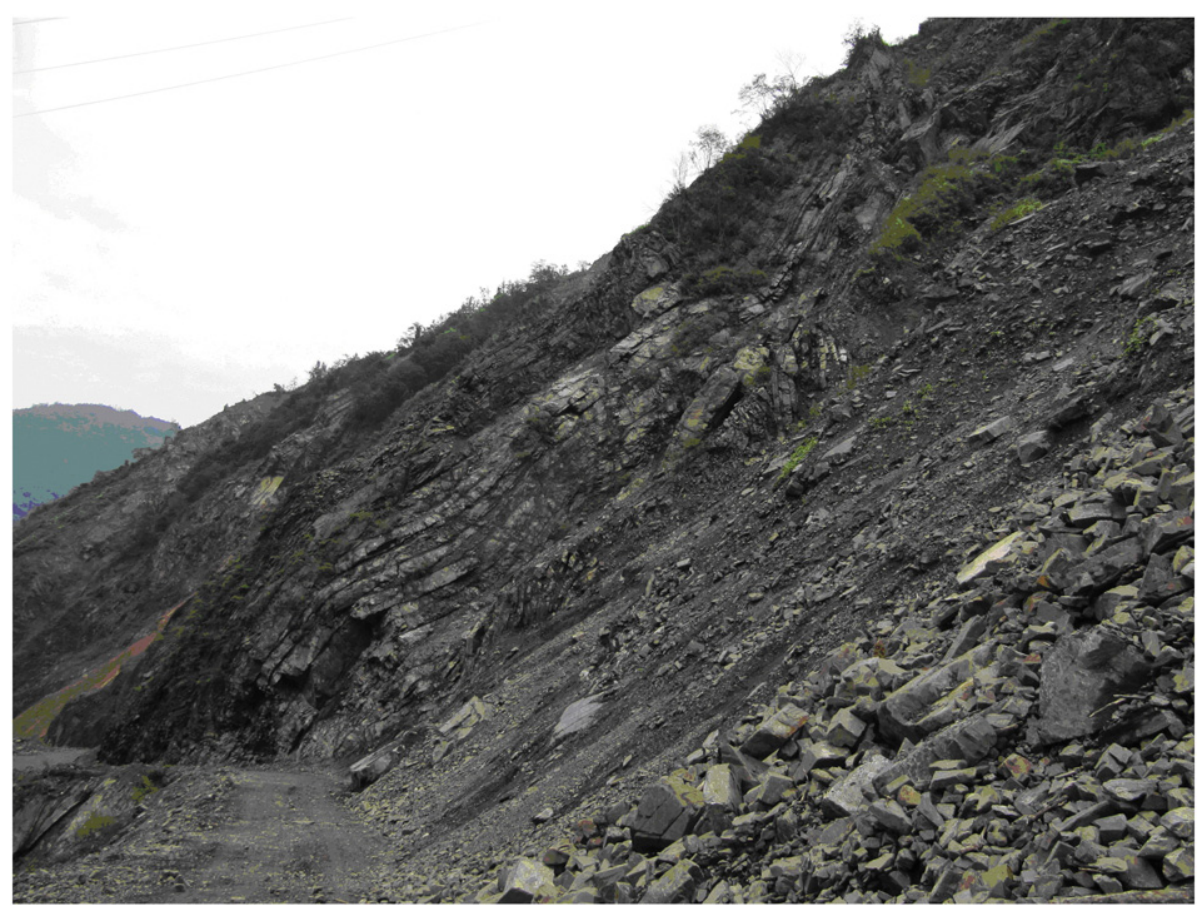

Fig. 1. One case of buckling failure triggered by 2008 Wenchuan earthquake. Adapted from Yang (2011)

of the slab and $l_{0}$ is the driving segment of the slab, $P$ is the residual driving force of unit width along the interlayer, $q$ is the gravitational load intensity, $k_{1}$ and $k_{2}$ represent the component of seismic coefficient in the normal and parallel direction to the slab. According to energy equilibrium, an analytical solution is derived for on the slip buckling slope failure taking into account both the effect of earthquake and pore water pressure expressed as follows.

The work done by residual driving force of $P$ is

$\Delta T_{1}=P \Delta$

where $\Delta$ is the shortening amount of the slab induced by $P$, and can be calculated as

$\Delta=\int_{0}^{l} \sqrt{\left(1+\left(y^{\prime}\right)^{2}\right)} d x-l$

where $y$ is the deflection curve, and $y^{\prime}$ is the first derivatives of $y$.

Making Taylor expansion and omitting second order and higher, $\Delta$ can be expressed as

$\Delta=\frac{1}{2} \int_{0}^{l}\left(y^{\prime}\right)^{2} d x$

Substituting Eq. (3) into Eq. (1),

$\Delta T_{1}=\frac{1}{2} P \int_{0}^{l}\left(y^{\prime}\right)^{2} d x$

The work done by the self weight of the buckling segment is

$\Delta T_{2}=\frac{1}{2} \int_{0}^{l} q(l-x)\left(y^{\prime}\right)^{2} \sin \alpha d x$

where $\alpha$ is the slope angle.
The work done by pore water pressure is

$$
\Delta T_{3}=\left\{\begin{array}{c}
\int_{0}^{l_{1}} y r_{w}\left(l_{1}-x\right) \sin \alpha d x, l_{1}<l \\
\int_{0}^{l} y r_{w}\left(l_{1}-x\right) \sin \alpha d x, l_{1} \geq l
\end{array}\right.
$$

where $r_{w}$ is the water density and $l_{1}$ is the distribution length of the groundwater along the slab.

The work done by seismic force is

$$
\Delta T_{4}=\int_{0}^{l} k_{1} q y d x+\frac{1}{2} \int_{0}^{l} k_{2} q(l-x)\left(y^{\prime}\right)^{2} d x
$$

The strain energy caused by the buckling stored in the slab is

$\Delta u_{1}=\frac{1}{2} \int_{0}^{l} E I\left(y^{\prime \prime}\right)^{2} d x$

where $E$ and $I$ are the elastic modulus and the moment of inertia of the slab respectively according to elastic theory (Timoshenko and Goodier, 1970), and $y^{\prime \prime}$ is the second derivatives of $y$.

The potential energy increment caused by the self-weight of the beam is equal to

$\Delta u_{2}=\int_{0}^{l} q y \cos \alpha d x$

Energy equilibrium is expressed as,

$\Delta T_{1}+\Delta T_{2}+\Delta T_{3}+\Delta T_{4}=\Delta u_{1}+\Delta u_{2}$

According to elastic theory (Timoshenko and Goodier, 1970), the deflection curve $y$ can be rewritten as

$y=a_{1}\left(1-\cos \frac{2 \pi x}{l}\right)+a_{2}\left(1-\cos \frac{4 \pi x}{l}\right), \quad 0 \leq x \leq l$ 
a

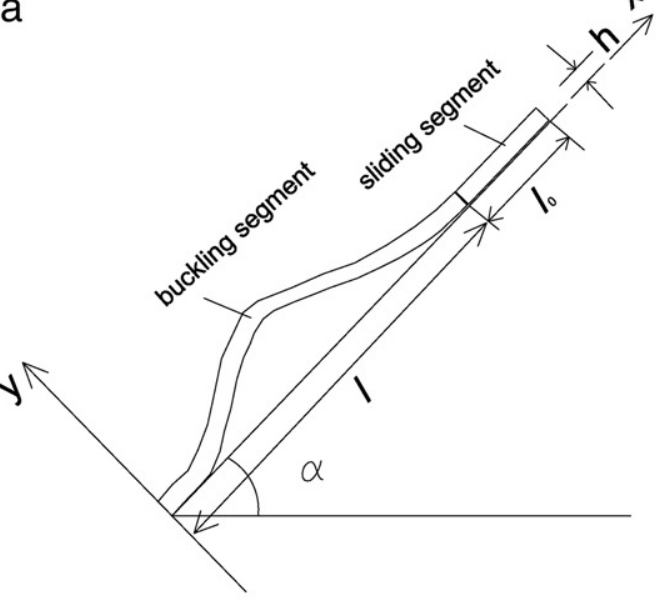

b
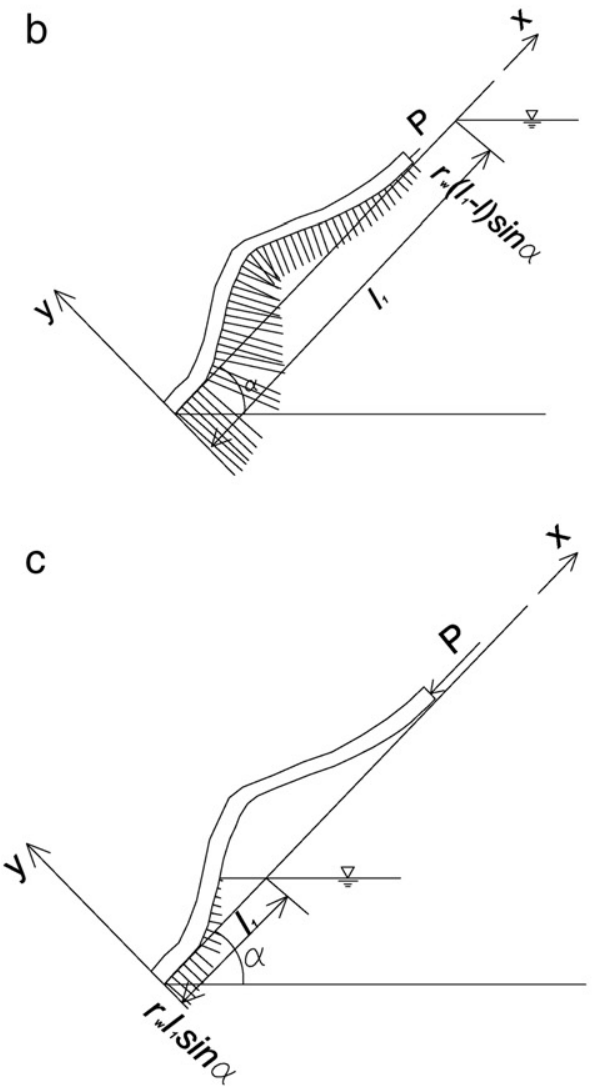

Fig. 2. The mechanical model of slip-buckling slope failure affected by earthquake and pore water pressure (a) geometric condition; (b) mechanical condition in the case of groundwater level is over the buckling segment $\left(l_{1} \geq l\right)$; (c) mechanical condition in the case of groundwater level is under the buckling segment $\left(l_{1}<l\right)$. where $a_{1}$ and $a_{2}$ are the coefficients.

$$
\text { If } x>l, y=0 \text {. }
$$

Thus

$\Delta T_{1}=\frac{P}{2}\left(a_{1}^{2} \frac{2 \pi^{2}}{l}+a_{2}^{2} \frac{8 \pi^{2}}{l}\right)$

$\Delta T_{2}=\frac{1}{2} q \sin \alpha\left(a_{1}^{2} \pi^{2}+4 a_{2}^{2} \pi^{2}\right)$
$\Delta T_{3}=\left\{\begin{array}{l}r_{w} \sin \alpha\left[\frac{1}{2}\left(a_{1}+a_{2}\right) l_{1}^{2}-\frac{a_{1} l^{2}}{4 \pi^{2}}\left(1-\cos \frac{2 \pi l_{1}}{l}\right)-\frac{a_{2} l^{2}}{16 \pi^{2}}\left(1-\cos \frac{4 \pi l_{1}}{l}\right)\right], l_{1}<l \\ r_{w} l\left(l_{1}-\frac{1}{2} l\right)\left(a_{1}+a_{2}\right) \sin \alpha, l_{1} \geq l\end{array}\right.$

$\Delta T_{4}=k_{1} q\left(a_{1}+a_{2}\right) l+\frac{1}{2} k_{2} q\left(\pi^{2} a_{1}^{2}+4 \pi^{2} a_{2}^{2}\right)$

$\Delta u_{1}=\frac{1}{2} E I\left(a_{1}^{2} \frac{8 \pi^{4}}{l^{3}}+a_{2}^{2} \frac{128 \pi^{4}}{l^{3}}\right)$

$\Delta u_{2}=q l \cos \alpha\left(a_{1}+a_{2}\right)$.

(1) In the case of groundwater level over the buckling segment In this case, $l_{1} \geq l$, substituting Eqs. (12)-(17) in Eq. (10) yields

$$
\begin{aligned}
& \left(a_{1}^{2} \frac{4 \pi^{2}}{l^{2}}+a_{2}^{2} \frac{16 \pi^{2}}{l^{2}}\right)\left[2 P+l q\left(\sin \alpha+k_{2}\right)\right] \\
& -2 E I\left(a_{1}^{2} \frac{16 \pi^{4}}{l^{4}}+a_{2}^{2} \frac{256 \pi^{4}}{l^{4}}\right) \\
& +8 r_{w}\left(l_{1}-\frac{1}{2} l\right)\left(a_{1}+a_{2}\right) \sin \alpha+8 q\left(a_{1}+a_{2}\right)\left(k_{1}-\cos \alpha\right) \\
& =0 .
\end{aligned}
$$

\section{Assuming}

$A=\frac{4 \pi^{2}}{l^{2}}$,Eq. (18) is written as

$\left(a_{1}^{2} A+4 A a_{2}^{2}\right)\left[2 P+l q\left(\sin \alpha+k_{2}\right)\right]$

$-2 E I\left(a_{1}^{2} A^{2}+16 a_{2}^{2} A^{2}\right)$

$+8 r_{w}\left(l_{1}-\frac{1}{2} l\right)\left(a_{1}+a_{2}\right) \sin \alpha+8 q\left(a_{1}+a_{2}\right)\left(k_{1}-\cos \alpha\right)$

$=0$.

\section{Assuming that}

$F=\left(a_{1}^{2} A+4 A a_{2}^{2}\right)\left[2 P+l q \sin \alpha\left(\sin \alpha+k_{2}\right)\right]$

$-2 E I\left(a_{1}^{2} A^{2}+16 a_{2}^{2} A^{2}\right)$

$+8 r_{w}\left(l_{1}-\frac{1}{2} l\right)\left(a_{1}+a_{2}\right) \sin \alpha+8 q\left(a_{1}+a_{2}\right)\left(k_{1}-\cos \alpha\right)$

$=0$

and then

$\frac{\partial F}{\partial a_{1}}=2 A a_{1}\left[2 P+l q\left(\sin \alpha+k_{2}\right)\right]-4 A^{2} E I a_{1}$

$+8 r_{w}\left(l_{1}-\frac{1}{2} l\right) \sin \alpha+8 q\left(k_{1}-\cos \alpha\right)=0$

$2 A a_{1}\left[2 P+l q\left(\sin \alpha+k_{2}\right)\right]-4 A^{2} E I a_{1}$

$+8 r_{w}\left(l_{1}-\frac{1}{2} l\right) \sin \alpha+8 q\left(k_{1}-\cos \alpha\right)=0$

$a_{1}=\frac{4 q \cos \alpha-4 q k_{1}+2 l r_{w} \sin \alpha-4 l_{1} r_{w} \sin \alpha}{A\left[2 P+l q\left(\sin \alpha+k_{2}\right)\right]-2 A^{2} E I}$

$\frac{\partial F}{\partial a_{2}}=8 A a_{2}\left[2 P+l q\left(\sin \alpha+k_{2}\right)\right]-64 A^{2} E I a_{2}$

$+8 r_{w}\left(l_{1}-\frac{1}{2} l\right) \sin \alpha+8 q\left(k_{1}-\cos \alpha\right)=0$

$a_{2}=\frac{4 q \cos \alpha-4 q k_{1}+2 l r_{w} \sin \alpha-4 l_{1} r_{w} \sin \alpha}{4 A\left[2 P+l q\left(\sin \alpha+k_{2}\right)\right]-32 A^{2} E I}$. 
If the slab is buckled, $y \rightarrow \infty$, then $a_{1} \rightarrow \infty$ or $a_{2} \rightarrow \infty$.

If $a_{1} \rightarrow \infty$, the critical equation can be written as

$2 P+l q\left(\sin \alpha+k_{2}\right)-2 A E I=0$.

If $a_{2} \rightarrow \infty$, the critical equation can be written as

$2 P+l q\left(\sin \alpha+k_{2}\right)-8 A E I=0$.

Due to the groundwater level is not over the slope, that is $l_{1} \leq$ $\left(l+l_{0}\right)$, then

$P=q l_{0} \sin \alpha+k_{2} q l_{0}-\left[q l_{0} \cos \alpha-k_{1} q l_{0}-\frac{1}{2} r_{w}\left(l_{1}-l\right)^{2} \sin \alpha\right] \tan \phi-c l_{0}$.

Substituting Eq. (28) into Eqs. (26) and (27) respectively yields

$2 q l_{0}\left(k_{2}+\frac{l}{2 l_{0}} k_{2}+k_{1} \tan \phi\right)$
$=2 A E I+2 c l_{0}+2 q l_{0} \sin \alpha\left(\frac{\tan \phi}{\tan \alpha}-1\right)-r_{w}\left(l_{1}-l\right)^{2} \sin \alpha \tan \phi-l q \sin \alpha$

$2 q l_{0}\left(k_{2}+\frac{l}{2 l_{0}} k_{2}+k_{1} \tan \phi\right)$

$=8 A E I+2 c l_{0}+2 q l_{0} \sin \alpha\left(\frac{\tan \phi}{\tan \alpha}-1\right)-r_{w}\left(l_{1}-l\right)^{2} \sin \alpha \tan \phi-l q \sin \alpha$.

Therefore Eqs. (29) and (30) are critical condition for the slab buckling.

(2) In the case of groundwater level under the buckling segment In this case, $l_{1}<l$, then we can have

$$
\begin{aligned}
& \left(A a_{1}^{2}+4 A a_{2}^{2}\right)\left[2 P+q l \sin \alpha+k_{2} q l\right] \\
& +\frac{4 r_{w} \sin \alpha}{l}\left[\left(a_{1}+a_{2}\right) l_{1}^{2}-\frac{a_{1} l^{2}}{2 \pi^{2}}\left(1-\cos \frac{2 \pi l_{1}}{l}\right)-\frac{a_{2} l^{2}}{8 \pi^{2}}\left(1-\cos \frac{4 \pi l_{1}}{l}\right)\right] \\
& -2 E I\left(a_{1}^{2} A^{2}+16 a_{2}^{2} A^{2}\right)-8 q \cos \alpha\left(a_{1}+a_{2}\right)=0=F
\end{aligned}
$$

$\frac{\partial F}{\partial a_{1}}=2 A a_{1}\left[2 P+q l \sin \alpha+k_{2} q l\right]+\frac{4 r_{w} \sin \alpha}{l}\left[l_{1}^{2}-\frac{l^{2}}{2 \pi^{2}}\left(1-\cos \frac{2 \pi l_{1}}{l}\right)\right]$
$-4 E I A^{2} a_{1}-8 q \cos \alpha=0$.

The coefficient follows from Eq. (32) as

$a_{1}=\frac{Q}{A\left[2 P+q l\left(\sin \alpha+k_{2}\right)\right]-2 E I A^{2}}$

where

$Q=4 q \cos \alpha-\frac{2 r_{w} \sin \alpha}{l}\left[l_{1}^{2}-\frac{l^{2}}{2 \pi^{2}}\left(1-\cos \frac{2 \pi l_{1}}{l}\right)\right]$.

Similarly

$a_{2}=\frac{R}{4 A\left[2 P+q l\left(\sin \alpha+k_{2}\right)\right]-32 E I A^{2}}$ where

$R=4 q \cos \alpha-\frac{2 r_{w} \sin \alpha}{l}\left[l_{1}^{2}-\frac{l^{2}}{8 \pi^{2}}\left(1-\cos \frac{4 \pi l_{1}}{l}\right)\right]$.

If $a_{1} \rightarrow \infty$, we have the same equation as (26).

If $a_{2} \rightarrow \infty$, we have the same equation as (27).

Due to $l_{1}<l$,

$P=q l_{0} \sin \alpha+k_{2} q l_{0}-\left(\cos \alpha-k_{1}\right) q l_{0} \tan \phi-c l_{0}$

Substituting Eqs. (37) into (26) and (27) respectively, we can have

$2 q l_{0}\left(k_{2}+\frac{l}{2 l_{0}} k_{2}+k_{1} \tan \phi\right)$

$=2 E I A+2 c l_{0}+2 q l_{0} \sin \alpha\left(\frac{\tan \phi}{\tan \alpha}-1\right)-q l \sin \alpha$

$2 q l_{0}\left(k_{2}+\frac{l}{2 l_{0}} k_{2}+k_{1} \tan \phi\right)$

$=8 E I A+2 c l_{0}+2 q l_{0} \sin \alpha\left(\frac{\tan \phi}{\tan \alpha}-1\right)-q l \sin \alpha$.

Therefore Eqs. (38) and (39) are critical condition for the slab buckling.

If we don't consider the effect of pore water pressure and earthquake effect, we have the critical equations as

$2 E I A+2 c l_{0}+2 q l_{0} \sin \alpha\left(\frac{\tan \phi}{\tan \alpha}-1\right)-q l \sin \alpha=0$

$8 E I A+2 c l_{0}+2 q l_{0} \sin \alpha\left(\frac{\tan \phi}{\tan \alpha}-1\right)-q l \sin \alpha=0$.

\section{Tangjiashan coseismic landslide}

Tangjiashan coseismic landslide is located on the right side of Jianjiang River, $3.2 \mathrm{~km}$ upstream of Beichuan County, Sichuan Province, China. It was triggered by Wenchuan earthquake occurring on May 12, 2008 with Mw 8.3 according to Chinese Earthquake Administration-CEA (Mw 7.9 according to the USGS) (Wang et al., 2009). The landslide claimed 84 deaths. A quake dam formed blocking Jianjiang River with the volume about $2.037 \times 10^{7} \mathrm{~m}^{3}$ and creating a barrier lake - Tangjiashan barrier lake. The dam has the length of $611.8 \mathrm{~m}$, the maximum width of $803.4 \mathrm{~m}$ along the river and the height of 82-124 $\mathrm{m}$ according to Hu et al. (2009) (see Figure 3). The lake has been successfully discharged on June 10, 2008.

The landslide is about $2.3 \mathrm{~km}$ from the hanging wall of the YingxiuBeichuan active fault, the main coseismic fault of the earthquake. The landslide occurred on a consequent slope at the lower segment of Qingping formation, Cambrian system, which consists of gray black marlstone, limestone, siliceous rock, and siltstone. These geological layers are interbedded, which makes the slope structurally weak and prone to landslide. They have attitude of NW330 $-340^{\circ} \angle 45^{\circ}$ with varied thickness of $8-30 \mathrm{~cm}$. The slope is located at about $1.2 \mathrm{~km}$ upstream of Kuzhuba dam. The crest of the slope is $1552 \mathrm{~m}$, the crown of the landslide is about $1200 \mathrm{~m}$, and the reservoir water level is $664.7 \mathrm{~m}$. There are two gullies developed at the both sides of the slope. The toe area of the landslide is just located at the bottom of the river bed, with altitude of about $650 \mathrm{~m}$. The original slope was about $35^{\circ}-40^{\circ}$ with a little convex before the landslide occurred (see Figure 4) (Hu et al., 2009). Fig. 5 shows the typical cross section of the slope before sliding.

There are series of folds developed in the upstream side near the landslide (see Figure 6). The slope where the landslide occurred is located at one wing of an overturned anticline (Li et al., 2010). It can be 


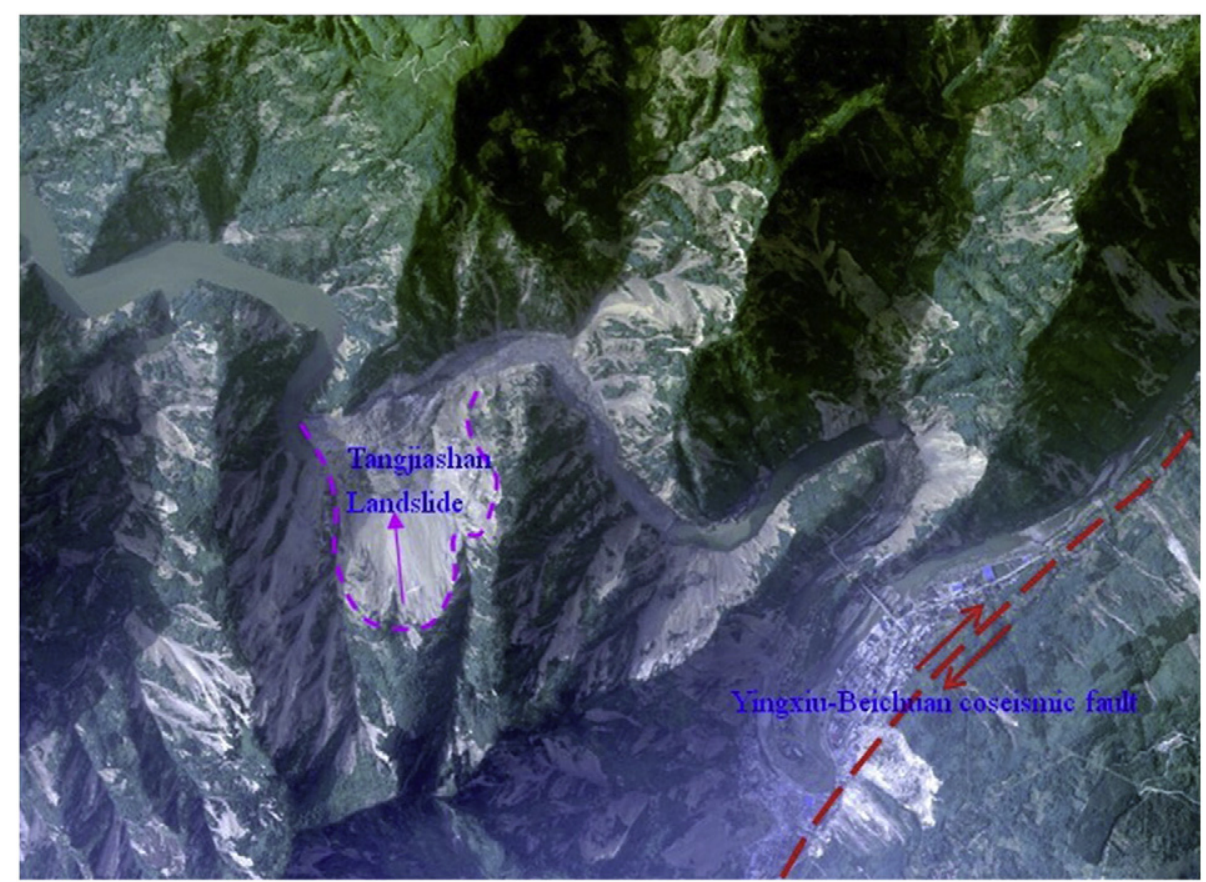

$1 \mathrm{~km}$

Fig. 3. The image of Tangjiashan landslide.

deducted that this area has experienced strong tectonic movements and the strata subjected to interlayer dislocations leading to weak shearing zone. Some interlayer shear zones were observed developing in the slope during the post-earthquake investigation. There are many traces left on the bed plane of the limestone (see Figure 7), which indicates that the slide can occur in two possible ways. One is that the buckling failure occurred first at the foot of the slope and then the slide is inducted at the upper slope along the interlayer shear zone. The other possible way is that the buckling process is not involved in the landsliding which is dominated by a translational slope movement along the interlayer shear zone accelerating by the downcutting of Jianjiang River. To understand the process of Tangjiashan landslide, a retrospective study is carried out using the proposed analytical solution.

The intact rock of Tangjiashan landslide area has a density of 2.50$2.64 \mathrm{~g} / \mathrm{cm}^{3}$, elastic moduli of 12.80-13.02 GPa, Poisson ratio of 0.150.20 , uniaxial compressive strength of 69.8-109 MPa, Brazilian tensile strength of 7.02-8.41 MPa, internal friction angle of 37.2-42.0 and cohesive strength of 8.75-9.23 MPa (Dong, 2010). In situ rock block tilt tests indicated that the internal friction angle of the bedding plane is lower than $36^{\circ}$. have

If the buckling process was not involved in the landslide, we will

Fos $=\frac{\left[q\left(l+l_{0}\right) \cos \alpha-k_{1} q\left(l+l_{0}\right)-\frac{1}{2} r_{w} l_{1}^{2} \sin \alpha\right] \tan \phi+c\left(l+l_{0}\right)}{k_{2} q\left(l+l_{0}\right)+q\left(l+l_{0}\right) \sin \alpha}$

where Fos is the safety factor of the slope before landslide.

In this case, $l_{1}$ is far less than $l+l_{0}$, and the slide surface is smooth, clean and good persistent as observed in the field, we can ignore the effect of water and cohesion, then Eq. (41) can be written as

Fos $=\frac{\left(\cos \alpha-k_{1}\right) \tan \phi}{k_{2}+\sin \alpha}$.
Before the earthquake $\left(k_{1}=k_{2}=0\right)$, Fos of the slope equals $\tan \varphi$ $(\tan \alpha=1)$.

The slope was stable before the earthquake, which means that $\tan \varphi$ should be larger than 1 . However we will always have the Fos lower than 1 even we used the largest possible value of $\varphi=36^{\circ}$ (Fos $=\tan$ $\varphi=0.73$ ). The friction angle required to stabilize the slope is even larger than the internal friction angle of the intact rock in the area as noted above. Therefore we can conclude that the slip buckling process might have involved in the slope movement but did not reach the critical state before the earthquake.

Taking the buckling process into account, we will have the following formulae based on Eq. (38)

$k_{2}+\frac{l}{2 l_{0}} k_{2}+k_{1} \tan \phi=\frac{E I A}{q l_{0}}+\frac{\sqrt{2}}{2}(\tan \phi-1)-\frac{l}{2 l_{0}} \frac{\sqrt{2}}{2}$.

Before the earthquake, we have seismic coefficient $k_{1}=k_{2}=0$. Substituting $k_{1}, k_{2}$ and the internal friction angle $\varphi=36^{\circ}$ into Eq. (43), we have

$l-\frac{2.829 E I A}{q}+0.54 l_{0}=0$

where $E=12.91 \mathrm{GPa}, q=25,700 h, A=\frac{4 \pi^{2}}{l^{2}}, I=\frac{h^{3}}{12}$, and $h$ is the thickness of the landslide with a mean value of about $20 \mathrm{~m}$. According to Fig. $5, l+l_{0}=\frac{1552-650}{\sin \alpha}=1275.6 \mathrm{~m}$. There is no valid root for Eq. (44).

During the earthquake, Zhou et al. (2009) indicated that PGA of the landslide area is $0.6 \mathrm{~g}$ in NS and WE, and $0.4 \mathrm{~g}$ in UD. Thus, we have seismic coefficient $k_{1}=k_{2}=0.707$. Substituting $k_{1}$ and $k_{2}$ into Eq. (43), we have

$l-1.414 \frac{E I A}{q}+2 l_{0}=0$ 
a

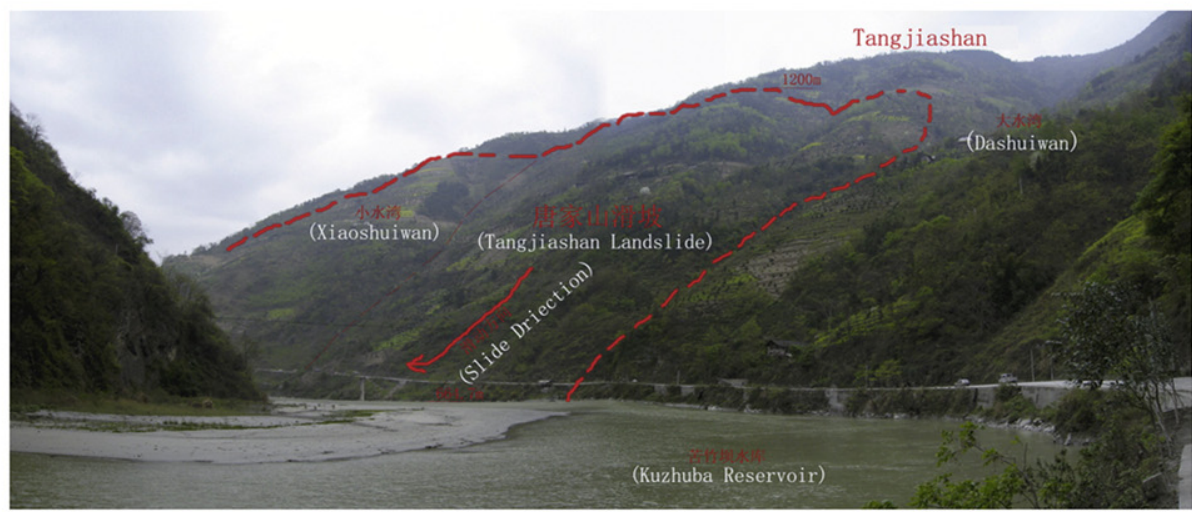

b

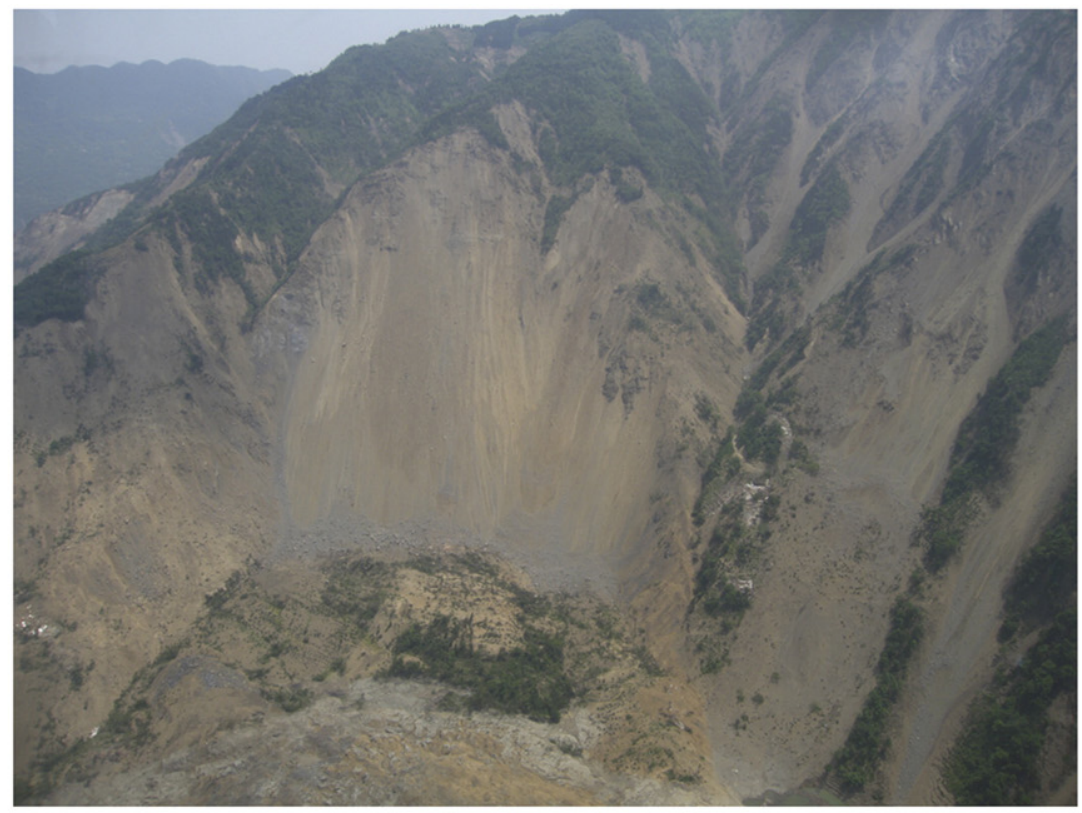

C

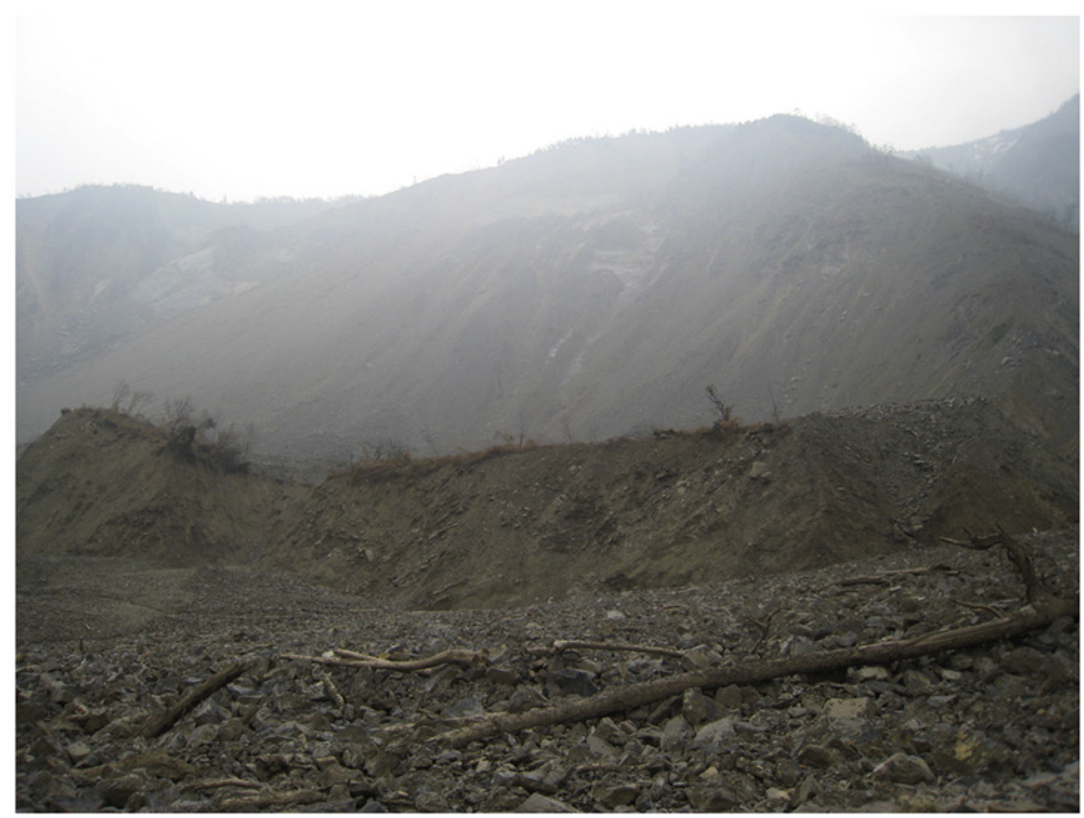

Fig. 4. The photography of the Tangjiashan landslide (a) before the earthquake (the photo is provided by Prof. Shi Yubing); (b) after the earthquake taken at the helicopter (the photo is provided by Prof. Shi Yubing); (c) after the earthquake taken at the foot. 


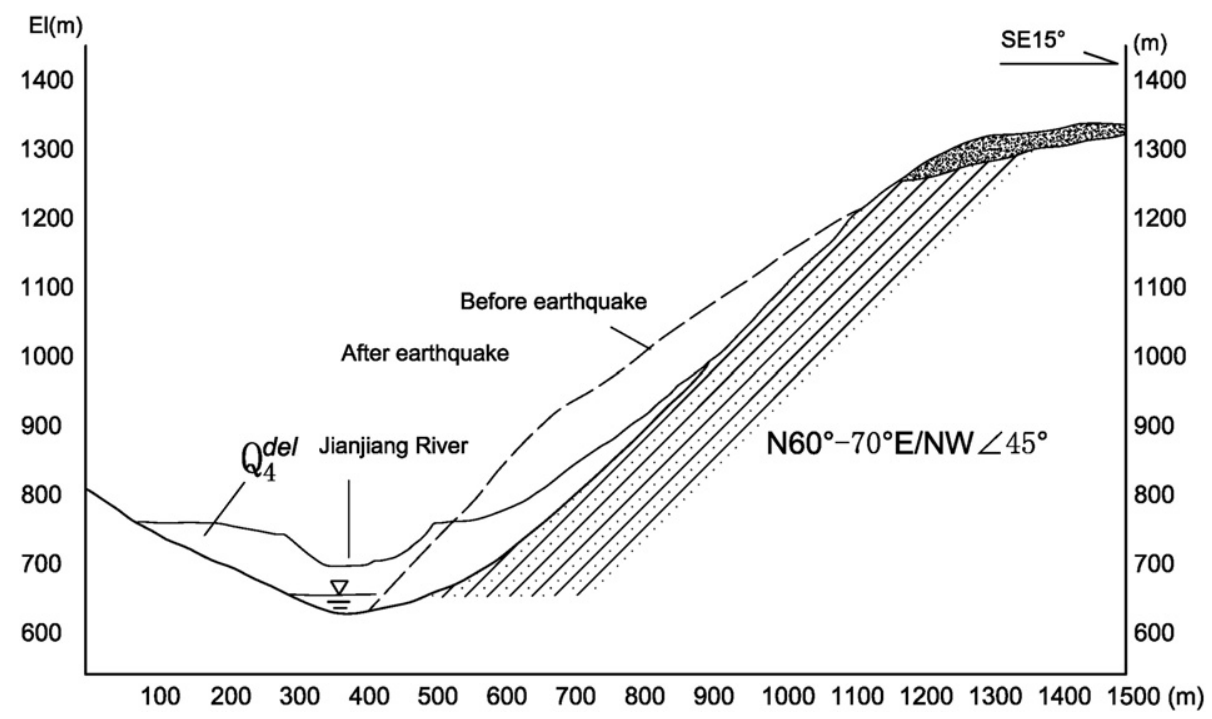

Fig. 5. Typical cross section of the slope. Revised after Dong (2010).

There is only one real root as $l=712.58 \mathrm{~m}$, which well satisfies with in-situ condition.

If we take Eq. (39), substituting $k_{1}=k_{2}=0$ into Eq. (39), we will have

$$
l-\frac{11.316 E I A}{q}+0.54 l_{0}=0
$$

Substituting $k_{1}=k_{2}=0.707$ into Eq. (39), we will have

$$
l-5.656 \frac{E I A}{q}+2 l_{0}=0 \text {. }
$$

As we know that Eqs. (46) and (47) didn't have valid solution.

From above, it can be concluded that the slip buckling process involved in the slope movement before the earthquake, and reached its critical state and lead to fail at last during Wenchuan earthquake.
This conclusion is also validated by overturned layer that occurred at the bottom of the landslide. The buckling segment is about $712.6 \mathrm{~m}$ and the driving segment is $563.0 \mathrm{~m}$. Meanwhile, we can also conclude that Eq. (38) is more plausible to evaluate the buckling process of Tangjiashan landslide during the earthquake.

\section{Discussions and conclusions}

Retrospective study indicates that Tangjiashan landslide is a typical buckling failure case triggered by the Wenchuan earthquake. If no buckling deformation is involved, the slope would not remain stable before the earthquake which is not in agreement with the real scenario. The slope should experience slipping and buckling deformation before sliding. After overcoming the buckling and frictional barrier, the potential energy stored in the slope turned into the high kinetic energy. However

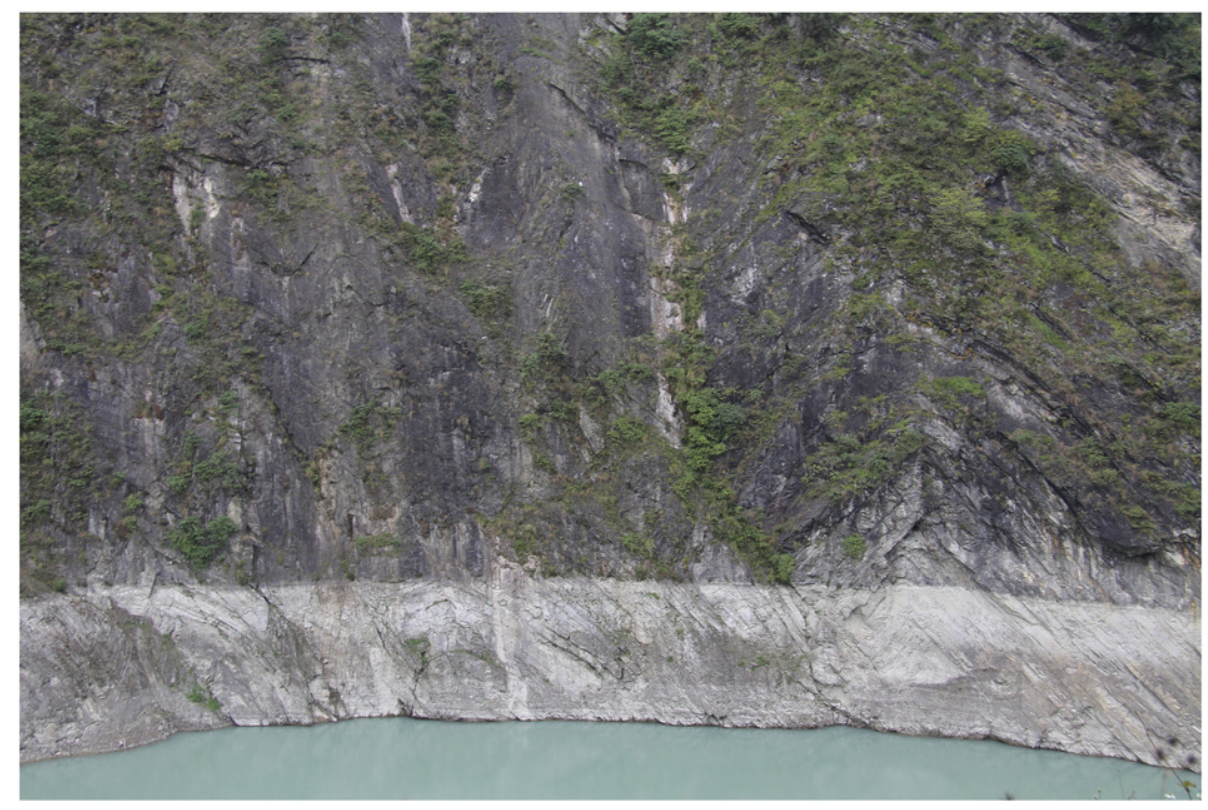

Fig. 6. Series of folds developed in the upstream side of the landslide. 


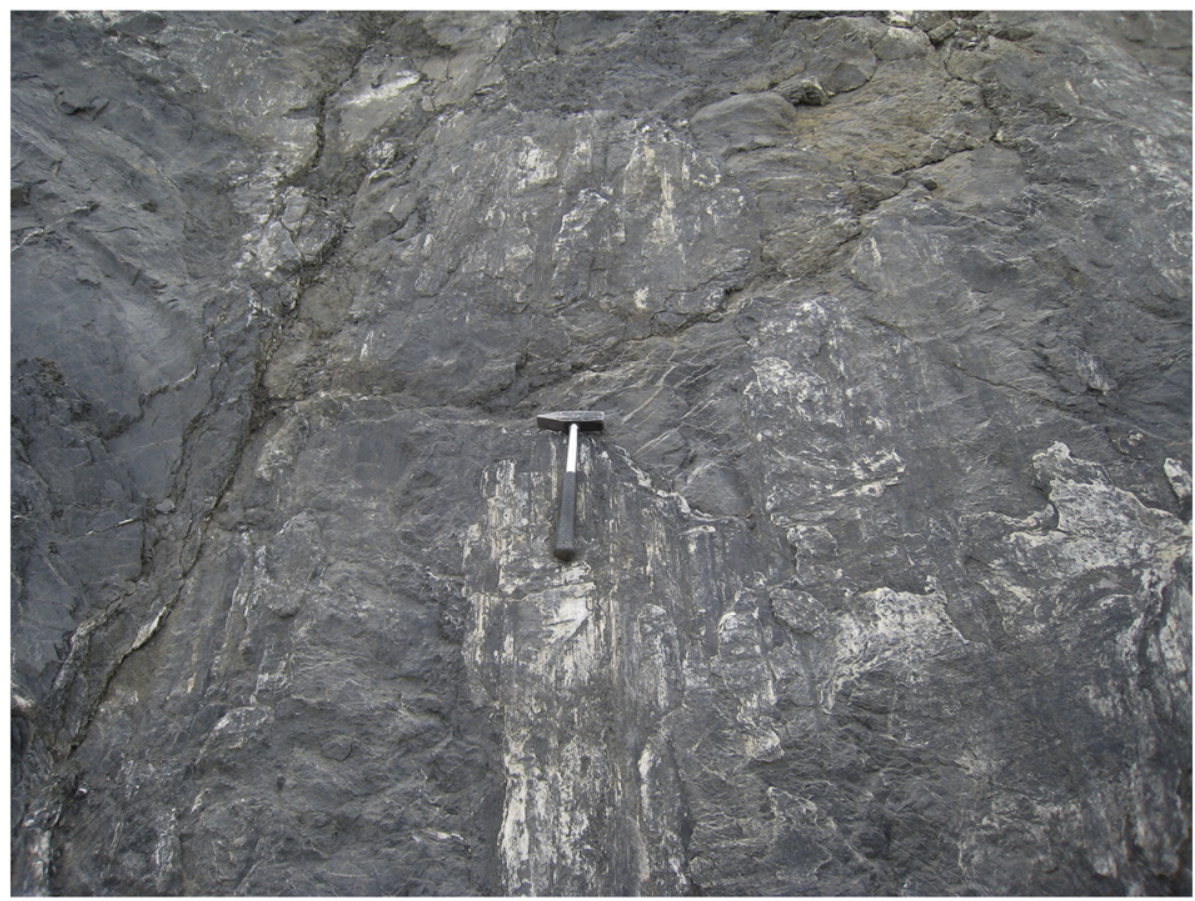

Fig. 7. The traces left on the sliding bed plane.

due to a short run out (about $540 \mathrm{~m}$ ), the landslide body was not severely disturbed and keeps fair good layered structure leading to the high stability of the barrier dam.

The application indicated that the proposed model has a potential to assess the stability condition of the consequent slope involving buckling deformation. The model is also suitable for different pore pressure situations. Eqs. (29) and (30) can be used to evaluate the stability of the slope with potential buckling failure during earthquake when the water level is under the buckling segment $\left(l_{1}<l\right)$, while Eqs. (38) and (39) should be used when the water level is over the buckling segment $\left(l_{1}>l\right)$.

\section{Acknowledgments}

The authors would like to thank Prof. Shi Yubing for his impressive photos of Fig. 4a and b. This work is supported by the National Science Foundation of China under grant nos. 41172272 and 41272354 and Chinese Academy of Science under Knowledge Innovation Project under grant no. KZCX2-EW-QN108.

\section{References}

Adhikary, D.P., Mühlhaus, H.B., Dyskin, A.V., 2001. A numerical study of flexural buckling of foliated rock slopes. Int. J. Numer. Anal. Methods Geomech. 25, 871-884.

Cavers, D.S., 1981. Simple methods to analyze buckling of rock slopes. Rock Mech. 14 $87-104$.
Dong, J., 2010. Study on Dynamic Responses and Sliding Failure Process of Rock Slope Under Earthquake. (Ph.D Dissertation) Institute of Geology and Geophysics, Chinese Academy of Sciences, p. 57 (Table 4-2, In Chinese with English Abstract).

Froldi, P., Lunardi, P., 1995. Buckling failure phenomena and their analysis. In: Rossmanith, H.P. (Ed.), Mechanics of Jointed and Faulted Rock. Balkema, Rotterdam, pp. 595-604

Hu, X.W., Huang, R.Q., Shi, Y.B., Lv, X.P., Zhu, H.Y., Wang, X.R., 2009. Analysis on blocking river mechanism of Tangjiashan landslide and dam-breaking mode of its barrier dam. Chin. J. Rock Mech. Eng. 28 (1), 181-189 (In Chinese with English Abstract).

Li, S., Li, X., Zhang. J., Hao, J., Li, S., Wang, Y., 2010. Study of geological origin mechanism of Tangjiashan landslide and entire stability of landslide dam. Chin. J. Rock Mech. Eng. 29 (Suppl.1), 2908-2915.

Pant, S.R., Adhikary, D.P., 1999. Implicit and explicit modelling of flexural buckling of foliated rock slopes. Rock Mech. Rock. Eng. 32 (2), 157-164.

Pereira, L.C., Lana, M.S., 2013. Stress-strain analysis of buckling failure in phyllite slopes. Geotech. Geol. Eng. 31, 297-314.

Qin, S., Jiao, J.J., Wang, S., 2001. A cusp catastrophe model of instability of slip-buckling slope. Rock Mech. Rock. Eng. 34 (2), 119-134.

Sun, G., 1988. Rock Mass Structure Mechanics. Science Press, Beijing, P.R. China, pp. 355-362 (in Chinese).

Timoshenko, S., Goodier, J.N., 1970. Theory of Elasticity, 3d ed. McGraw-Hill, New York,.

Wang, W., Chigira, M., Furuya, T., 2003. Geological and geomorphological precursors of the Chiu-fen-erh-shan landslide triggered by the Chi-chi earthquake in central Taiwan. Eng. Geol. 69, 1-13.

Wang, F., Cheng, Q., Highland, L., Miyajima, M., Wang, H., Yan, C., 2009. Preliminary investigation of some large landslides triggered by the 2008 Wenchuan earthquake, Sichuan Province, China. Landslide 6, 47-54.

Yang, G., 2011. Study on Failure Mechanism and Dynamic Response Rules of Rock Slope Under Earthquake. (Ph. D Dissertation) Institute of Geology and Geophysics, Chinese Academy of Sciences, p. 28 (Fig. 2-10, In Chinese with English Abstract).

Zhou, R., Lai, M., Yu, H., Long, C., Wang, S., Kang, C., Liang, M., 2009. Strong motion records of Wenchuan Ms8.0 earthquake from digital strong earthquake networks in Sichuan and its neighbouring regions. Chin. J. Rock Mech. Eng. 29 (9), 1850-1858 (In Chinese with English Abstract). 